\title{
Degradation of Concrete Structures from the Climate Change Perspective
}

\author{
Pablo Benítez ${ }^{1,2}$, Fernanda Rodrigues ${ }^{2}$, Sudip Talukdar ${ }^{3}$ and Sergio Gavilán ${ }^{4}$ \\ ${ }^{1}$ FIUNI, Facultad de Ingeniería, Universidad Nacional de Itapúa, Encarnación, 6000, Paraguay, \\ pablo.benitez@fiuni.edu.py \\ ${ }^{2}$ RISCO, Department of Civil Engineering, University of Aveiro, Aveiro, 3810-193, Portugal, \\ mfrodrigues@ua.pt \\ ${ }^{3}$ Department of Civil Engineering, British Columbia Institute of Technology, Burnaby, BC 3700, \\ Canada, stalukdar1@bcit.ca \\ ${ }^{4}$ FIUNA, Faculty of Engineering, National University of Asuncion, San Lorenzo, 2160, Paraguay, \\ ingsergiogavilan@gmail.com
}

\begin{abstract}
The negative effects of climate change are underway despite the global efforts to mitigate them and the future scenario are unsettling. Climate change poses critical challenges to urban environments and highlights the need for research its impacts on the built environment. One of the most significant effects of climate change on reinforced concrete structures is associated with the carbonation of these structures. The increase of parameters such as temperature and carbon dioxide jeopardise the degradation of such structures by carbonation-induced corrosion. This paper presents the results of the monitoring and analysis of a set of buildings that determine carbonation as the main degradation mechanism of structures in Paraguay. Through the application of a previously developed carbonation model, the worsening of the carbonation-induced degradation has been determined after considering the climate change effects in the coming 50 years. The outcomes of the study determined that the poor quality of the structures in Paraguay cause premature degradation in them. Furthermore, considering climate change effects, it has been determined that this phenomenon could accelerate corrosion failure times in reinforced concrete structures.
\end{abstract}

Keywords: Carbonation, Climate Change, Real Carbonation Data, Reinforcement Corrosion.

\section{Introduction}

Nowadays, ensuring that structures can withstand the environmental factors that determine their degradation has become a big challenge for engineers, who often are subject to a limited budget when are designing their projects. The study of the degradation of structures caused by environmental phenomena did not reach a significant interest until a few decades ago when climate change became tangible as a critical problem that affects the daily integrity of human beings. Furthermore, such as the buildings built in earlier times (e.g., bridges, cathedrals, castles, and so on), it is now possible to classify several of the 20th-century concrete structures as modern heritage, whose maintenance has cultural and historical value for each country.

Rehabilitation, maintenance and repair of buildings play an important role in ensuring its performance in the long term, so they have a significant impact on the adaptation of buildings to climate change. Recent studies have shown widespread concern regarding the regulations in the construction industry in relation to durability, which are based on historical climate data. Therefore, a comprehensive study of the climate change impacts on the degradation of the structure is necessary (de Wilde and Coley, 2012). Perhaps one of the most meaningful 
conclusions of the Intergovernmental Panel on Climate Change (IPCC) in its fifth assessment report was that the climate change effect comprises a problem that cannot be removed immediately. That is, the concentrations of greenhouse gases in the world are so high that their reduction or stabilization could not be possible for several centuries (IPCC, 2013).

Although civil engineering historically has covered its knowledge based on physical and mechanical stresses to establish the durability conditions of a structure, the effect of climate change has forced to expand knowledge in a deeper way towards the environmental and chemical stresses that influence directly on the integrity of infrastructures worldwide. Therefore, a neglected area is the impact of climate change on RC structures, where it is necessary to adapt future designs to ensure that infrastructures have adequate capacity and have sufficient durability to deal with the consequences of climate change (Talukdar, 2013).

Under this context, the degradation of reinforced concrete (RC) structures could be significant considering carbonation-induced corrosion. Carbonation is a natural phenomenon produced by the chemical reaction between cement hydroxides and the atmospheric carbon dioxide $\left(\mathrm{CO}_{2}\right)$ (Broomfield, 2007). This degradation mechanism is directly influenced by three climatic parameters that are associated to the effects of climate change: $\mathrm{CO}_{2}$ concentration, temperature and relative humidity. Therefore, the study of the carbonation phenomenon as a degradation mechanism of concrete structures has been a spotlight of engineers since the emergence of climate change.

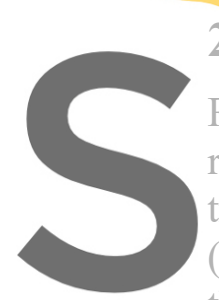

\section{Carbonation in.RC Structures}

Regarding carbonation-induced degradation, the interpretation requires a quantitative

transport mechanism th

(Taffese and Sistonen,

the structure and subsequent the spalling of the cove

Then, the corrosion rate directly affects the extension of the service life of the RC structures

Register forhfree at bottps//www.scipedia.com to download the version without the watermark

\subsection{Effects of Climate Change on Concrete Degradation}

Several studies agree that climate change will cause new considerations and establish new conditions for the construction industry. Due to climate change, the risks of damage induced by carbonation in concrete can increase by more than $16 \%$ by the year 2100 , which means that one in six structures will suffer additional and costly corrosion damage due to this phenomenon. It has also been found that, as a consequence of climate change, the corrosion rate could increase by $15 \%$ if the temperature increases by $2{ }^{\circ} \mathrm{C}$ (Stewart et al., 2011, 2012).

Research developed for concrete infrastructures in China has determined, taking into account the same climatic parameters mentioned above, that the depth of carbonation could increase by $45 \%$ in reinforced concrete structures by the year 2100 (Peng and Stewart, 2016). On the other hand, Stewart et al. concluded that in some regions of Australia, the risks of damage induced by carbonation can increase even by more than $400 \%$ by the year 2100 (Stewart et al., 2011). Later, other studies showed that global warming could advance the time of failure by $31 \%$ or decrease the service life up to 15 years for moderate levels of aggressiveness (Bastidas-Arteaga et al., 2013). 
The long life of the buildings is perhaps the most palpable problem since most of the buildings built now must continue in service within the next 50-100 years. However, the most efficient way for adaptation is taken the proper actions before these buildings are built, i.e. during the design stage. Therefore, it is crucial to develop policies and strategies that reduce long-term risks for new buildings, encourage early adaptation where possible to existing buildings and, at least, adopt a precautionary approach to the uncertain risks of climate change (Camilleri et al., 2001).

\subsection{Carbonation-Induced Degradation in Paraguay}

Carbonation is one of the most frequent phenomenon that leads to degradation problems in structures located in Paraguay. The index of relative humidity and the tropical temperature makes a propitious place for the carbonation to propagate in the structures and jeopardise its durability due to the reinforcement corrosion. In this paper, a database with 327 carbonation depth measurements in different structures of Paraguay has been analyzed in order to know the real carbonation rate in RC structures. The construction industry in Paraguay has had significant growth in the last decade. However, the first infrastructures built in the country lacked adequate control, whereby currently a poor quality in buildings is evidenced that compromises its durability.

The carbonation data of the case study corresponds to buildings located in urban area. Considering that the study was conducted in existing buildings, the carbonation depth was measured by applying the phenoiphthalein test. Three measurements were taken for each structural element and tho these structures was bet

century. On the other

constructive characteris

should be noted that int
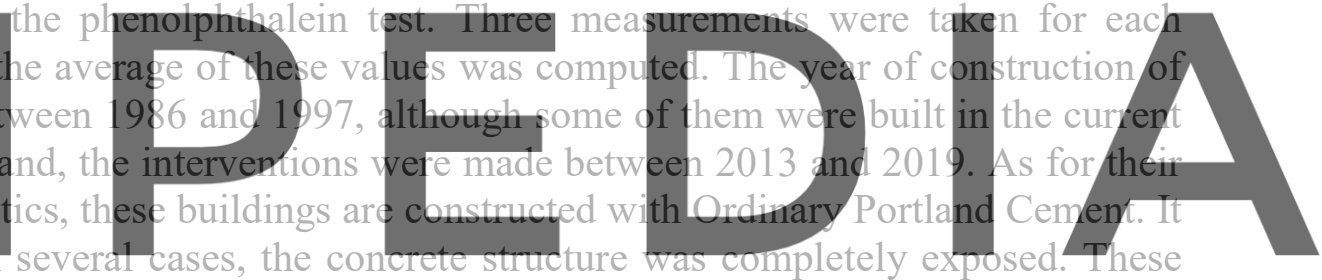

cases correspond to unfinished buildings, a very common case in the country when construction

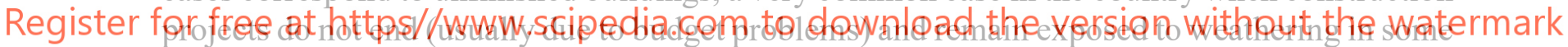

cases for more than ten years even.

Through a statistical analysis of the real carbonation data, the mean value and the standard deviation for the cover thickness and the carbonation depth are shown in Table 1. These results suggest that can be expected a carbonation depth that has almost the same thickness than the cover. This result is quite important since the probability of corrosion onset is too high considering the loss of alkalinity of concrete due to carbonation. On the other hand, the results shown in Table 1 have been classified according to the structural elements of the building. After this classification, it has been seen that the slabs were the most compromised elements from the point of view of the corrosion initiation by carbonation. This is deduced since the mean cover thickness $(12.30 \mathrm{~mm})$ was practically equal to the mean of the carbonation depth $(12.15 \mathrm{~mm})$ in the structures.

Considering the carbonation tests results, an analysis was performed in order to determine the carbonation-induced corrosion risk. It was possible to classify three conditions of degradation for the analysed structures: with corrosion risk, without corrosion risk, and the condition of imminent corrosion initiation. For this purpose, a structure without corrosion risk has been considered when the cover of the structure is not yet carbonated or, at least, the 
carbonation front is not in a critical zone that may induce corrosion. This consideration is specifically referred to that an immediate carbonation-induced corrosion is not expected. However, as has been studied in the literature, corrosion could be induced by other mechanisms and this study has focused only on carbonation.

Table 1. Results for carbonation depth and concrete cover of the case study.

\begin{tabular}{ccc}
\hline Variable & $\begin{array}{c}\text { Main } \\
\text { Value }\end{array}$ & $\begin{array}{c}\text { Standard } \\
\text { Deviation }\end{array}$ \\
\hline $\begin{array}{c}\text { Carbonation Depth } \\
(\mathrm{mm})\end{array}$ & 18.0 & 7.13 \\
\hline $\begin{array}{c}\text { Cover Thickness } \\
(\mathrm{mm})\end{array}$ & 18.1 & 8.32 \\
\hline
\end{tabular}

Furthermore, the condition referring to structures with corrosion risk includes those where the carbonation front had exceeded the cover thickness. This implies that the reinforcement is wholly embedded in a carbonated concrete, leaving it vulnerable to corrosion due to the suppression of the passive protection layer. The last condition referred to imminent initiation of corrosion considers what has been established in Yoon et al. (2007), in which the corrosion begins when the carbonation front is located at least within $5 \mathrm{~mm}$ of the rebar surface, being necessary an immediate intervention.

Then, this analysis has shown that almost half of the cases analysed (49.91\%) present a considerable corrosion risk or imminent corrosion initiation caused by carbonation. That means the carbonated thickne durability of the structure the buildings analysed ago, can be considered of its corrosion degradat
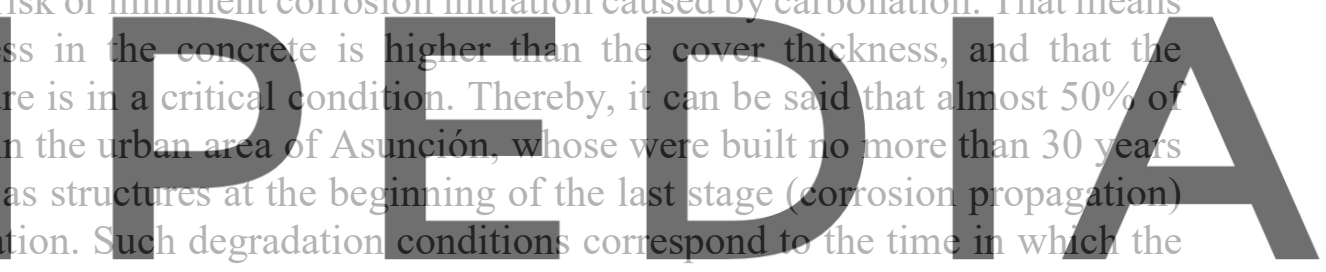

interventions were carried out in the structures of the case study. Hence, the structures without

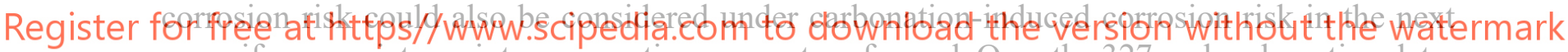
years if appropriate maintenance actions are not performed. Over the 327 real carbonation data, the result of the analysis is depicted in Figure 1.

\section{Degradation Conditions}

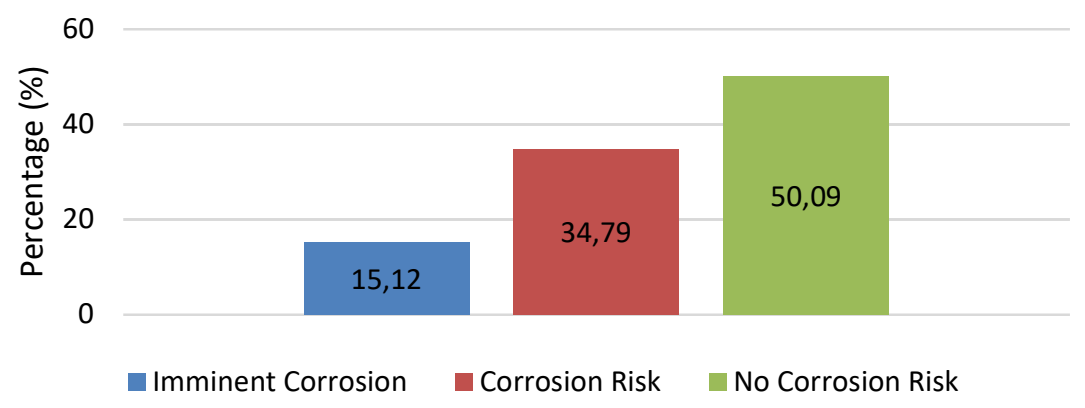

Figure 1. Degradations conditions considering inspection results.

In essence, through the case study shown in this section, it was possible to illustrate that carbonation is a common problem in the concrete structures of Paraguay. The lack of control 
during the execution of the works often triggers in structures without the adequate conditions that guarantee their durability. Therefore, according to the study developed in this section, the cover thickness is referred to as the most influential parameter to reduce the time to corrosion initiation. In this way, a rigorous control is recommended during the elaboration of these structures that guarantee, not only the adequate thickness but a good cover quality through a low porosity.

\section{Carbonation Modelling}

Recently, many degradation models have sought to link the phenomenon of climate change and its influence on degradation parameters, which represents a significant advance. On the other hand, the estimation of the service life of structures under the influence of cracking or the system of loads to which a real structure is subjected is still insufficiently studied due to its complexity. The numerical degradation model applied in this paper to estimate the carbonation depth in structures due to the climate change effect was the model developed in (Talukdar et al., 2012). This model was considered suitable to represent the estimated carbonation-induced degradation over time since it is formulated as a function of a climatic scenario and concrete properties. This feature allows the model to predict the degradation of concrete structures under consideration of climate change, which is directly related to the context of this research.

The carbonation model applied in this research is a deterministic one-dimensional numerical diffusion model for a gaseous medium through a porous substrate based on Fick's Second Law.

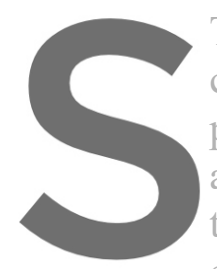

The model has been validated based on experimental resutts obtained in an accelerated

carbonation chamber.

phenomenon considerin

and concentration of gas

temperature and carbon

effects can be included within the carbonatic
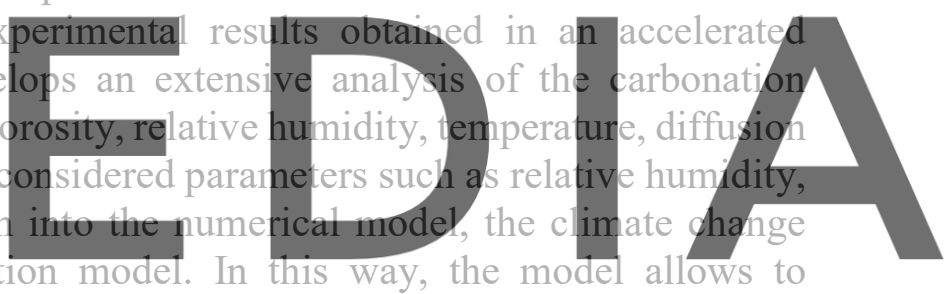

determine the concentration of $\mathrm{CO}_{2}$ and $\mathrm{Ca}(\mathrm{OH})_{2}$ within the concrete as a function of time by

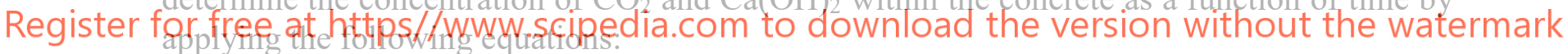

$$
\begin{gathered}
\frac{\delta}{\delta t}\left[\mathrm{CO}_{2(a q)}\right]=D \frac{\delta^{2}}{\delta x^{2}}\left[\mathrm{CO}_{2(\mathrm{~g})}\right] \mathrm{HRT}-k\left[\mathrm{CO}_{2(a q)}\right]\left[\mathrm{Ca}(\mathrm{OH})_{2(a q)}\right] \\
\frac{\delta}{\delta t}\left[\mathrm{Ca}(\mathrm{OH})_{2(a q)}\right]=D \frac{\delta^{2}}{\delta x^{2}}\left[\mathrm{Ca}(\mathrm{OH})_{2(a q)}\right]-k\left[\mathrm{CO}_{2(a q)}\right]\left[\mathrm{Ca}(\mathrm{OH})_{2(a q)}\right]
\end{gathered}
$$

Where $\mathrm{CO}_{2(a q)}$ and $\mathrm{Ca}(\mathrm{OH})_{2(a q)}$ are the aqueous concentration of $\mathrm{CO}_{2}$ and $\mathrm{Ca}(\mathrm{OH})_{2}$ respectively $\left(\mathrm{mol} / \mathrm{m}^{3}\right), \quad D$ is the effective diffusivity of the carbon dioxide into the concrete $\left(\mathrm{m}^{2} / \mathrm{s}\right), H R$ is the relative humidity $(\%), T$ is the temperature $(\mathrm{K}), k$ is the reaction rate constant $\left(\mathrm{m}^{3} / \mathrm{mol} / \mathrm{s}\right), \mathrm{CO}_{2(\mathrm{~g})}$ is the atmospheric concentration of carbon dioxide $\left(\mathrm{mol} / \mathrm{m}^{3}\right)$. Therefore, by solving Equations (1) and (2) simultaneously, it is possible to obtain the concentrations of both solutions involved in the carbonation reaction using the "Method of Lines" proposed by Cutlip and Shacham (Cutlip and Shacham, 2007). Further details of the mathematical derivation of the model and the values of the parameters in both equations can be found on (Talukdar et al., 2012). 
Equations (1) and (2) model the corrosion initiation stage. For the corrosion propagation stage, the model employs an analytical thick-walled uniform cylinder which assumes that the generation of a volume of corrosion products (rust) around the corroding steel causes an expansion in the diameter of the steel. Within the formulation of this stage of corrosion degradation, the model considers parameters such as the activation energy and the reference current flow density which are not generally taken as constants by other models. These parameters may depend on the interaction between the concrete resistivity, the saturation level and the cover thickness.

\subsection{Carbonation Simulation Results}

The carbonation model provides a valuable perspective on how the carbonation front advances over time through concrete structures under the influence of climate change. After running the carbonation model in MATLAB, the results are shown in Table 2 regarding the ultimate carbonation depth (UCD) for two typical RC structures of Paraguay (20 and $25 \mathrm{MPa}$ ) considering two different climatic scenarios of the IPCC (RCP 4.5 and RCP 8.5). The UCD represents the maximum depth reached by the carbonation front during the simulations.

Furthermore, a control scenario is considered to be able to monitor the expected increase in the carbonation depth caused by the climate change effect. This control scenario is a scenario where the relative humidity and the mean annual temperature were held to the current values for Paraguay as $75.1 \%$ and $23.7^{\circ} \mathrm{C}$, respectively. On the other hand, it is also possible to

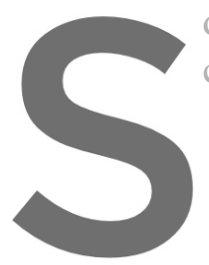
determine through the co carbonation, as well as th

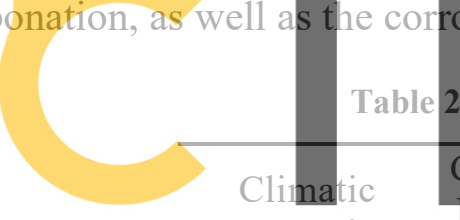

Scenario
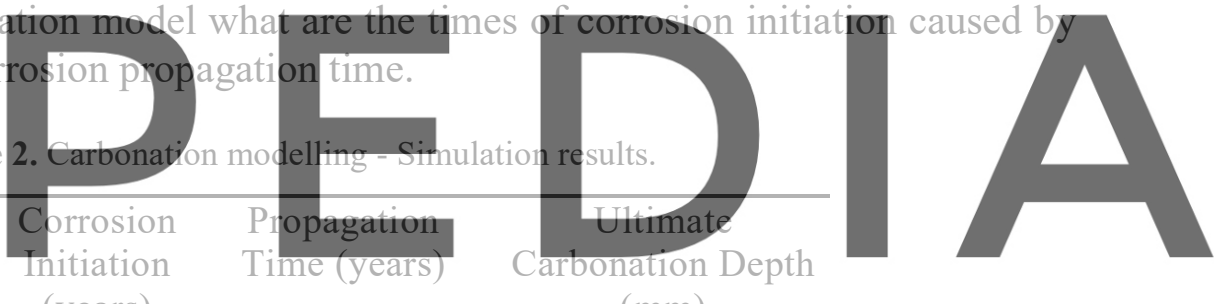

Register for free at https//wWW.scipedia. GQma to downlead the version without the watermark

\begin{tabular}{cccc} 
Control & 20.15 & 2.32 & 35 \\
\hline RCP 4.5 & 19.27 & 2.95 & 35.6 \\
\hline RCP 8.5 & 18.24 & 2.88 & 40 \\
\hline \multicolumn{5}{c}{ Strength: $25 \mathrm{MPa}-$ Cover thickness: $25 \mathrm{~mm}$} \\
\hline Control & 26.65 & 2.66 & 30 \\
\hline RCP 4.5 & 23.69 & 2.69 & 30.8 \\
\hline RCP 8.5 & 22.57 & 2.76 & 35 \\
\hline
\end{tabular}

After the application of the carbonation model, some conclusions can be drawn regarding the corrosion risk by carbonation in the concrete structures of Paraguay. Concrete structures would reach an UCD between 30 and $40 \mathrm{~mm}$ corresponding to a service life of 50 years, depending on the concrete quality and the climatic scenario predicted. Herein, the ultimate carbonation depth is considered as the maximum depth of carbonation front reached in the simulation and this parameter is subjected to the boundary conditions of the model. Moreover, it can be said that the RC structures in Paraguay would be under considerable corrosion risk considering the forecasting climate changes. Moreover, simulations have not shown alteration 
regarding the UCD between the control scenario and the best scenario. The difference was concerning the time, where the UCD is reached in the best climate scenario between $12 \%$ and $20 \%$ earlier than in the control scenario. On the other hand, the carbonation depth could increase between $14 \%$ and $16 \%$ for the worst-case scenario.

On the other hand, it has been found that the higher the strength of the structure, the greater the carbonation resistance, which is reflected in the corrosion initiation times. The main reason for this behaviour is the porosity of the material. The concrete strength is directly related to the porosity of the material so that the diffusion of gases within the concrete is limited in the materials of greater resistance. The numerical model applied in this paper considers that before the expansive pressure of the oxide is generated, it is necessary that the porous zone of the concrete/steel interface be wholly filled with the corrosion products (rust). This porous zone has been initially considered in the numerical model with a value of $10 \mu \mathrm{m}$. However, many other studies consider different values for this parameter ranging from $50 \mu \mathrm{m}$ to $100 \mu \mathrm{m}$ (Siemes et al., 1985; Broomfield, 2007). If the porous zone is increased by 50\%, the corrosion propagation time can be increased between 10 and 60\%. Therefore, the limit pf rust generation to fill this zone is quite influential in the simulation results obtained. That is, the concrete quality will always be a critical factor regarding the durability of RC structures.

\section{Conclusions}

Although there are several investigations related to the corrosion of concrete reinforcements in countries such as Chind, the United States, Australia and European countries, at the Latin
American level it was possible to confitm a lack of available research that can describe the sanne
problems under the specific circumstances of the region. In the specific dase of Paraguay,
is a developing country, the accessibility to information and the low number of it does not allow
to describe the state of degradation of the infrastructures scientifieally.
It was found that quality control during the construction process is of utmost importance to ensure a minimum concrete cover, which is one of the most critical factors on the initiation of

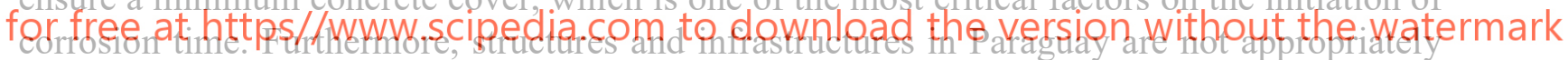

designed and executed according to the consideration of environmental effects. Regarding the degradation prediction modeis, one of the most significant handicaps is the difficuity in adopting the parameters in a precise and quantifiable way. It is true that these numerical models seek to describe, in an increasingly precise way, the natural behaviour of the degradation processes of structures. However, it is still necessary to carry out a lot of research in this area to achieve this objective entirely.

Concerning the carbonation model results for the structures of Paraguay, can be expected early degradation in the next years due to climate change effects. Thus, for the worst climate scenario, in the second half of this century is expected an average increase by $16 \%$, in the maximum carbonation depth regarding a control scenario for RC structures of 20 and $25 \mathrm{MPa}$. Meanwhile, the time to reach the same maximum carbonation depth of the control scenario can be reduced even in 8 years for the best climate scenario, depending on the quality of the concrete. After a sensitivity analysis through the carbonation model, it was found that the reduction of the concrete cover to a value of $10 \mathrm{~mm}$ provides a significant acceleration in the corrosion initiation time. Therefore, not only the concrete strength has to be monitored, but also the concrete cover. Perhaps one of the most concerning conclusions is given by the fact that the 
carbon dioxide accumulated in the earth's atmosphere cannot be reduced to acceptable levels until within a few centuries, even considering that greenhouse gas emissions were entirely and immediately reduced. Then, this situation suggests that the best strategy to deal with this problem involves adaptation measures rather than mitigation measures. From the engineering and constructions approach, this strategy must be proposed dynamically considering the accelerated change in the expected climate according to the IPCC scenarios.

Acknowledgments: This wok was funded by Project PTDC/ECI-EST/28439/2017 - POCI-01-0145-FEDER028439 - funded by European Regional Development Fund (ERDF) through COMPETE2020 and with financial support from FCT/MCTES through national funds (PIDDAC).

\section{ORCID}

Pablo Benítez: https://orcid.org/0000-0002-3607-0559

Fernanda Rodrigues: https://orcid.org/0000-0001-9127-7766

References

Ahmad, S. (2003). Reinforcement Corrosion in Concrete Structures , Its Monitoring and Service Life Prediction - a Review. Cement and Concrete Composites 25:459-71. doi: 10.1016/S0958-9465(02)00086-0

Bastidas-Arteaga, E., F. Schoefs, M. Stewart and X. Wang. (2013). Influence of Global Warming on Durability of Corroding RC Structures: A Probabilistic Approach. Engineering Structures 51:259-66. doi: 10.1016/j.engstruct.2013.01.006

Broomfield, J. (2007). Corrosion of Steel in Concrete. Understanding, Investigation and Repair - 2nd Edition. Taylor \& F. New York, USA.

Camilleri, M., R. Jaques Zealand. Building Resear

Cutlip, M. and M. Shacham. Excel, and Matlab. Secon Wilde, P. and Coley Environment, 55, 1-7. doi: 10.1016/j.buildenv.2012.0
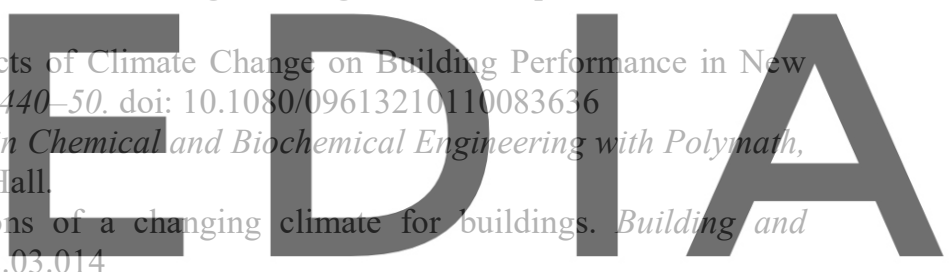

IPCC. (2013). Summary for policymakers, in: I.P.C.C. Stocker, T.F.D. Qin, G.-K. Plattner, M. Tignor, S.K. Allen,

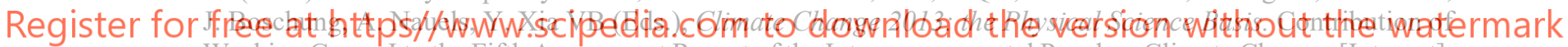
Working Group I to the Fifth Assessment Report of the Intergovernmental Panel on Climate Change. [Internet], United Kingdom and New York. Available from: http://www.climatechange2013.org/

Peng, L. and M. Stewart. (2016). Climate Change and Corrosion Damage Risks for Reinforced Concrete Infrastructure in China. Structure and Infrastructure Engineering 12(4):499-516. doi: $10.1080 / 15732479.2013 .858270$

Siemes, A., A. Vrouwenvelder and A. van den Beukel. (1985). Durability of Buildings - A Reliability Analysis. Heron, 30(3):3-48.

Stewart, M., X. Wang and M. Nguyen. (2011). Climate Change Impact and Risks of Concrete Infrastructure Deterioration. Engineering Structures 33:1326-37. doi: 10.1016/j.engstruct.2011.01.010

Stewart, M., X. Wang and M. Nguyen. (2012). Climate Change Adaptation for Corrosion Control of Concrete Infrastructure. Structural Safety 35:29-39. doi: 10.1016/j.strusafe.2011.10.002

Taffese, W. and E. Sistonen. (2013). Service Life Prediction of Repaired Structures Using Concrete Recasting Method: State-of-the-Art. Procedia Engineering, 57:1138-44. doi: 10.1016/j.proeng.2013.04.143

Talukdar, S. (2013). The Effects of Global Climate Change on Carbonation Induced Corrosion of Reinforced Concrete Structures. PhD Thesis, University of British Columbia. Vancouver, Canada.

Talukdar, S., N. Banthia and J. Grace. (2012). Carbonation in Concrete Infrastructure in the Context of Global Climate Change - Part 1 : Experimental Results and Model Development. Cement \& Concrete Composites 34:924-30. doi: 10.1016/j.cemconcomp.2012.04.011

Yoon, I., O. Çopuroğlu and K. Park. (2007). Effect of Global Climatic Change on Carbonation Progress of Concrete. Atmospheric Environment 41:7274-85. doi: 10.1016/j.atmosenv.2007.05.028 